\title{
Location and disturbance affect population genetic structure in four coral species of the genus Acropora on the Great Barrier Reef
}

\author{
P. Souter ${ }^{1}$, B. L. Willis ${ }^{2,3}$, L. K. Bay ${ }^{1,2}$, M. J. Caley $^{1}$, A. Muirhead ${ }^{1}$, \\ M. J. H. van Oppen ${ }^{1, *}$ \\ ${ }^{1}$ Australian Institute of Marine Science, PMB \#3, Townsville, Queensland 4810, Australia \\ ${ }^{2}$ ARC Centre of Excellence for Coral Reef Studies, and ${ }^{3}$ School of Marine and Tropical Biology, James Cook University, \\ Townsville, Queensland 4811, Australia
}

\begin{abstract}
The impact of a mass bleaching event on temporal and spatial population genetic structure in 4 scleractinian coral species in the Acropora aspera group was studied around the Palm Islands in the central Great Barrier Reef. Species status of sympatric populations of 2 of the 4 species, A. millepora and A. spathulata, was confirmed by the population genetic data; these species have recently been separated based on morphological and breeding characters. Spatial analyses of population samples from 2004 detected differences in the level of gene flow among locations. No significant genetic differentiation was inferred between conspecific populations at Orpheus and Pelorus Islands, which are both located in the northern part of the island group and separated by $\sim 1000 \mathrm{~m}$. In contrast, all populations at Fantome Island were genetically differentiated, despite this island being located only $11 \mathrm{~km}$ south. Sampling of A. millepora and A. pulchra in the year prior to the 1998 mass bleaching event enabled a temporal comparison across this event. The genetic composition of these populations changed between 1997 and 2004, but patterns of genetic differentiation among locations were similar in 1997 and 2004. Extensive mortality of these species following the 1998 bleaching event did not cause an apparent reduction in genetic diversity and identical multi-locus genotypes were encountered in both temporal samples, suggesting that re-growth of surviving genotypes contributed to the recovery of these populations. Comparisons among the 4 study species revealed lower genetic diversity in A. papillare, consistent with its low abundance throughout its distributional range.
\end{abstract}

KEY WORDS: Acropora - Climate change · Palm Islands · Central Great Barrier Reef · Genetic diversity $\cdot$ Genetic connectivity $\cdot$ Coral bleaching

\section{INTRODUCTION}

Coral reefs are threatened worldwide by anthropogenic disturbances, including destructive fishing, sedimentation, terrestrial run-off and the effects of greenhouse gas emissions (Hoegh-Guldberg 1999, Hughes et al. 2003, van Oppen \& Gates 2006, Lough 2008, Wilkinson 2008). Although a range of stressors can cause corals to bleach, manifested as the loss of endosymbiotic dinoflagellates and/or their photosynthetic pigments from host tissues (Weis 2008), mass coral bleaching events have most commonly occurred during extended periods of unusually warm and still weather, when water temperatures rise and light levels are high. Mass coral bleaching events have occurred on a worldwide scale on a few occasions in the last 2 decades, most notably in 1998 (Oliver et al. 2009), but the frequency of such extreme weather events is predicted to increase with climate change (Donner et al. 2005). Therefore, a thorough understanding of the population and community level responses of corals to bleaching is required to effectively manage coral reefs into the future. 
Severe bleaching is likely to reduce effective population sizes of reef corals, either directly through mortality or indirectly through reduced gene flow among populations due to reduced growth, fecundity and disease resistance of surviving corals (Michalek-Wagner \& Willis 2001, Bourne et al. 2009, Mydlarz et al. 2010), all of which would have fitness consequences for populations. Moreover, random genetic drift is likely to exacerbate loss of genetic diversity in small populations, which also reduces population fitness. Hence, smaller and more genetically isolated populations face greater risk of extinction than larger and more genetically diverse populations (Pannell \& Charlesworth $1999,2000)$. Indeed, population size and degree of isolation are among the most important criteria for listing species as endangered under the IUCN system (www. iucnredlist.org/static/categories_criteria_3_1).

Population genetic data can contribute to conservation efforts through enabling the estimation of effective population sizes, levels of genetic diversity, patterns of gene flow and the identification of conservation units. The identification of such units is particularly valuable if species are hard to distinguish using morphological characters. Many scleractinian corals display considerable morphological plasticity, and overlapping morphologies may occur between some species (Miller \& Babcock 1997, Flot et al. 2008). Furthermore, introgressive hybridisation (van Oppen et al. 2000, Willis et al. 2006) and the occurrence of cryptic species (Souter 2010) have the potential to obscure the units relevant for conservation purposes. The genus Acropora, the most abundant and species-rich Indo-Pacific scleractinian genus (Veron 2000), has been the subject of numerous genetic, morphological and breeding studies (reviewed in Willis et al. 2006). The genus is presently divided into 20 species groups based on morphology and growth form (Wallace 1999). One such group, the A. aspera group, is comprised of 7 morphologically distinct species, 5 of which are found in sympatry on the Great Barrier Reef (GBR). Some species within the group lack discrete breeding barriers, and hybridisation and introgression can occur among them (Willis et al. 1997, van Oppen et al. 2002). However, pre-mating isolation in no-sperm-choice crossing experiments has been demonstrated between 2 species in the group, A. millepora and A. spathulata (Willis et al. 1997). In combination with detailed morphological investigations (Wallace 1999), this has suggested the species status of $A$. spathulata, which was previously considered a 'thick branch morph' of A. millepora.

The 1998 coral bleaching event reduced coral cover in Acropora-dominated communities by over $50 \%$ in the Palm Islands, but bleaching patterns were patchy over small spatial scales $(<10 \mathrm{~km})$ (Marshall \& Baird 2000). Prior to the mass bleaching, exposed reef flats at both Pelorus and Orpheus were dominated by A. pul- chra (B. L. Willis pers. obs.; Fig. 1), but this species suffered close to $100 \%$ mortality on these reefs in 1998 (Page 1999, Gralton 2001); only small patches of live tissue at the bases of a few colonies could be located in 1999, despite extensive searching over many days (B. Willis pers. obs.). Analyses of video transects of the reef flat sites at Pelorus and Orpheus Islands recorded in 1998 and 1999 demonstrated a drop in overall percent cover of corals, from means of approximately $70 \%$ cover in 1998 to 5-10\% cover in March 1999 (Gralton 2001). In sympatric populations of A. millepora located on the deeper reef slope, $32 \%$ of all colonies suffered bleaching-induced, whole-colony mortality at Pelorus Island following the 1998 bleaching event (Baird \& Marshall 2002). By November 2001, percent coral cover had risen by more than $30 \%$ on the inner reef flat and slope at the Pelorus site, although this recovery was mostly attributed to encrusting and massive corals (Gralton 2001). The GBR experienced another major coral bleaching event in 2002, but the reefs around the Palm Islands remained mostly unaffected by this event (Oliver et al. 2009). While the extent of the 1998 bleaching at a community level indicates the intensity of this event, additional information at the population level is required to fully understand the evolutionary responses of corals to such disturbances (Day et al. 2008). Using high resolution molecular markers (microsatellites), we verified current morphological species boundaries for 4 species in the A. aspera group, examined spatial patterns in their population genetic structure at sites located within the Palm Island group, and analysed temporal patterns in their population genetic structure across 2 bleaching events.

\section{MATERIALS AND METHODS}

In 2004, a total of 564 colonies from 4 morphologically discrete species within the Acropora aspera group (A. millepora, A. spathulata, A. pulchra, and A. papillare) (Fig. 2) were sampled from 3 inshore reefs at SE Pelorus, NE Orpheus and NE Fantome Islands in the Palm Island group within the central GBR (Fig. 3). At the time of sampling, the corymbose species $A$. millepora and A. spathulata were common on outer reef flats and reef slopes at most locations around the Palm Islands. Although the arborescent species A. pulchra dominated inner reef flats at the sites prior to the 1998 bleaching event, it became locally extinct or very rare immediately after the event (B. L. Willis pers. obs.). Similarly, populations of the encrusting, digitate $A$. papillare sustained extensive mortality during the 1998 bleaching event and only occurred in low numbers on the reef crest at Pelorus and Orpheus in 2004. For 2 of the species (A. millepora and A. pulchra), addi- 


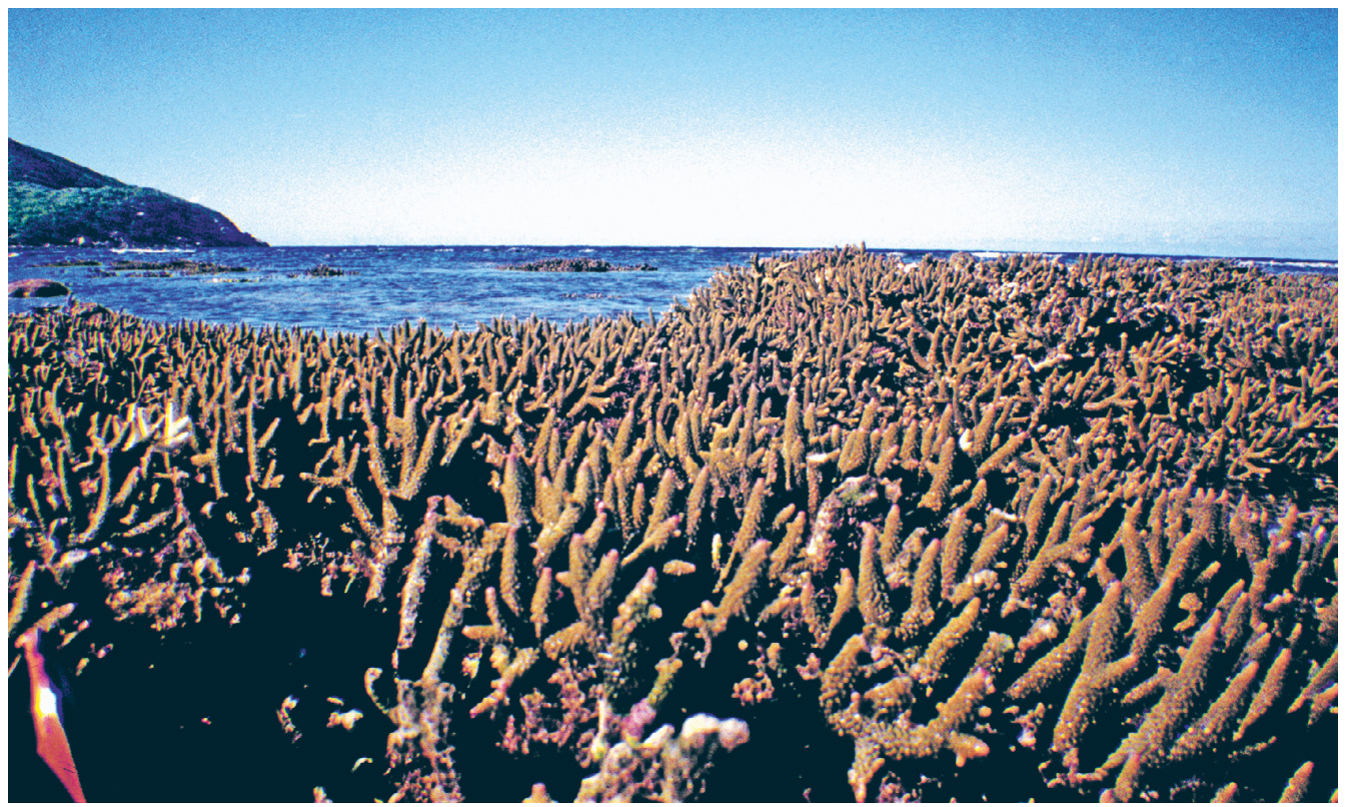

Fig. 1. Acropora pulchra at NE Orpheus Island in 1997. Only small patches of remnant tissue were found during extensive surveys in 1999
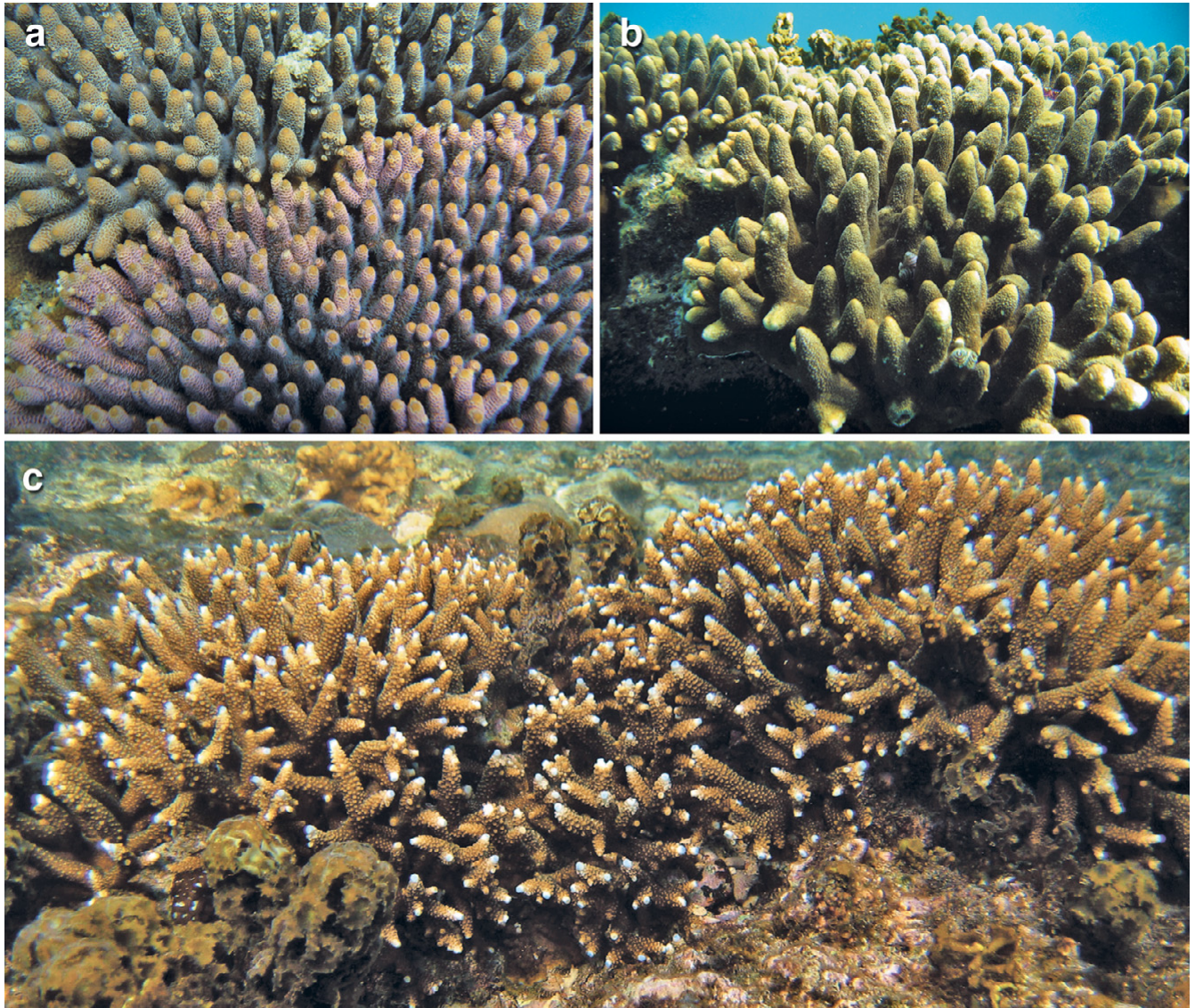

Fig. 2. Species included in the study: (a) Acropora spathulata (upper left) and A. millepora (lower right) in sympatry, (b) A. papillare and (c) A. pulchra 
tional samples collected from the same locations at Pelorus and Orpheus in 1997 were included in the study (see Table 1 for sample sizes). Samples were stored in $100 \% \mathrm{EtOH}$ at ambient temperature.

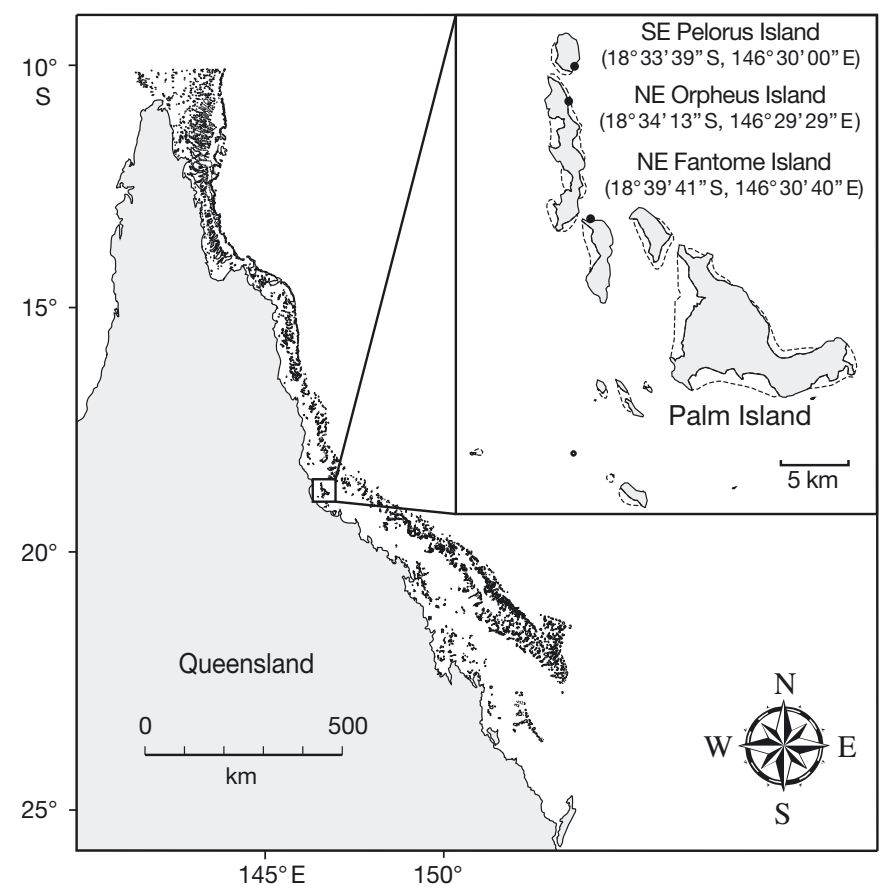

Fig. 3. Sampling locations in the Palm Island group in the central Great Barrier Reef
DNA was extracted following Wilson et al. (2002) and each colony was genotyped at 9 DNA microsatellite loci developed for Acropora millepora (van Oppen et al. 2007). PCR was carried out in 3 multiplex reactions as follows: Multiplex 1 comprised primer pairs Amil2_002 (forward HEX-labelled 5'), Amil5_028 (forward TET-labelled 5') and Amil2_006 (forward FAMlabelled $\left.5^{\prime}\right)$ at a final concentration of $0.1 \mu \mathrm{M}$ each primer. Multiplex 2 comprised Amil2_022 (forward TET-labelled 5'), Amil2_023 (forward HEX-labelled 5') and Apam3_166 (forward FAM-labelled 5') at a final concentration of $0.1 \mu \mathrm{M}$ each primer. Multiplex 3 comprised Amil2_007 (forward HEX-labelled 5'), Amil2_010 (forward FAM-labelled 5') and Amil2_012 (forward TET-labelled 5'). Amil2_007 primers were at $0.1 \mu \mathrm{M}$ each, the rest at $0.05 \mu \mathrm{M}$ each. Reactions were carried out in $10 \mu \mathrm{l}$ reaction comprising $5 \mu \mathrm{l}$ of $2 \times$ Master Mix (Qiagen ${ }^{\circledR}$ Multiplex PCR), $1 \mu$ l of $10 \times$ Primer Mix, $0.75 \mu \mathrm{l}$ of template and $3.25 \mu \mathrm{l}$ of Milli-Q water. Cycling conditions were $95^{\circ} \mathrm{C}$ for $15 \mathrm{~min} ; 35$ cycles of $94^{\circ} \mathrm{C}$ for $30 \mathrm{~s}, 50^{\circ} \mathrm{C}$ for $90 \mathrm{~s}, 72^{\circ} \mathrm{C}$ for $60 \mathrm{~s} ; 60^{\circ} \mathrm{C}$ for $30 \mathrm{~min}$ and held at $10^{\circ} \mathrm{C}$.

The Excel Microsatellite Toolkit (Park 2001) was used to identify identical multilocus genotypes (MLGs) that were likely to be a result of asexual reproduction within each population. The probability of identical (PID) MLGs being produced by random mating was calculated in GENCLONE (Arnaud-Haond \& Belkhir 2007) taking into account the level of inbreeding

Table 1. Acropora spp. Sample statistics. Sample labels given as species name, location, collection year (OI: Orpheus Island; FI: Fantome Island; PI: Pelorus Island). Number of colonies sampled (n), number of unique multi-locus genotypes $\left(N_{\mathrm{G}}\right)$, expected $\left(H_{\mathrm{E}}\right)$ and observed $\left(H_{\mathrm{O}}\right)$ heterozygosity, average allelic richness per sample $(A)( \pm \mathrm{SD})$ and Wright's inbreeding coefficient $\left(F_{\mathrm{IS}}\right)$. Bold $F_{\text {IS }}$ indicates a significant deficit of heterozygotes $(\mathrm{p}<0.005)$. Samples under the solid line are those where $\mathrm{n}<15$ that were excluded from the population genetic statistics. na: not applicable

\begin{tabular}{|lrrcccc}
\hline Sample & $\mathrm{n}$ & $N_{\mathrm{G}}$ & $H_{\mathrm{E}}$ & $H_{\mathrm{O}}$ & $A$ \\
\hline A. millepora PI 1997 & 18 & 18 & $0.630( \pm 0.092)$ & $0.493( \pm 0.041)$ & $7.11( \pm 3.14)$ & $\mathbf{0 . 2 2 2}$ \\
A. millepora PI 2004 & 50 & 50 & $0.620( \pm 0.080)$ & $0.585( \pm 0.025)$ & $6.43( \pm 3.14)$ & 0.058 \\
A. millepora OI 1997 & 17 & 17 & $0.672( \pm 0.096)$ & $0.529( \pm 0.043)$ & $6.88( \pm 3.36)$ & $\mathbf{0 . 2 1 8}$ \\
A. millepora OI 2004 & 50 & 50 & $0.647( \pm 0.069)$ & $0.580( \pm 0.023)$ & $6.98( \pm 3.59)$ & $\mathbf{0 . 1 2 1}$ \\
A. millepora NF 2004 & 50 & 50 & $0.648( \pm 0.068)$ & $0.602( \pm 0.025)$ & $6.47( \pm 3.47)$ & 0.071 \\
A. spathulata PI 2004 & 50 & 49 & $0.509( \pm 0.103)$ & $0.185( \pm 0.025)$ & $5.12( \pm 2.61)$ & 0.047 \\
A. spathulata OI 2004 & 50 & 50 & $0.516( \pm 0.105)$ & $0.492( \pm 0.025)$ & $5.27( \pm 2.62)$ & 0.046 \\
A. spathulata NF 2004 & 45 & 45 & $0.568( \pm 0.111)$ & $0.519( \pm 0.026)$ & $6.08( \pm 3.28)$ & $\mathbf{0 . 0 8 7}$ \\
A. pulchra PI 1997 & 35 & 30 & $0.445( \pm 0.112)$ & $0.367( \pm 0.031)$ & $4.80( \pm 3.12)$ & $\mathbf{0 . 1 8 0}$ \\
A. pulchra PI 2004 & 49 & 33 & $0.438( \pm 0.100)$ & $0.373( \pm 0.026)$ & $5.41( \pm 3.47)$ & $\mathbf{0 . 1 4 9}$ \\
A. pulchra NF 2004 & 53 & 43 & $0.485( \pm 0.108)$ & $0.396( \pm 0.025)$ & $5.73( \pm 3.20)$ & $\mathbf{0 . 1 8 4}$ \\
A. papillare PI 2004 & 50 & 33 & $0.289( \pm 0.107)$ & $0.186( \pm 0.021)$ & $2.88( \pm 1.96)$ & $\mathbf{0 . 3 5 9}$ \\
A. papillare OI 2004 & 25 & 21 & $0.323( \pm 0.114)$ & $0.154( \pm 0.027)$ & $2.60( \pm 1.50)$ & $\mathbf{0 . 3 5 2}$ \\
\hline A. aspera OI 2004 & 9 & 9 & $0.452( \pm 0.070)$ & $0.225( \pm 0.051)$ & $3.38( \pm 1.06)$ & na \\
A. aspera NF 2004 & 4 & 4 & $0.679( \pm 0.045)$ & $0.313( \pm 0.082)$ & $3.50( \pm 0.93)$ & na \\
A. aspera PI 1997 & 6 & 6 & $0.162( \pm 0.082)$ & $0.067( \pm 0.038)$ & $1.50( \pm 0.76)$ & na \\
A. spathulata PI 1997 & 11 & 11 & $0.563( \pm 0.120)$ & $0.477( \pm 0.061)$ & $3.63( \pm 2.33)$ \\
A. pulchra OI 2004 & 6 & 6 & $0.424( \pm 0.104)$ & $0.125( \pm 0.050)$ & $2.63( \pm 1.60)$ \\
A. papillare PI 1997 & 5 & 5 & $0.271( \pm 0.087)$ & $0.179( \pm 0.067)$ & $2.00( \pm 1.00)$ & na \\
na & \\
\hline
\end{tabular}


(Wright's inbreeding coefficient $F_{\text {IS }}$ ) of the sample. All but one of the identical MLGs within populations that were likely to have been produced asexually (PID < 0.01) were removed from the data set. Each population sample was checked for the presence of null alleles and scoring errors using the van Oosterhout algorithm in the software MICROCHECKER (van Oosterhout et al. 2004). This correction adjusts the allele and genotype frequencies in the population based on Hardy-Weinberg Equilibrium expectations. A dataset containing corrected allele frequencies and excluding loci that had null allele frequencies of over $30 \%$ was used for all subsequent population genetic analyses.

Despite being considered neutral, microsatellites may be subject to selective forces by linkage to functional genes. Hence, signatures of selection were detected by comparing locus-specific $F_{\mathrm{ST}}$ values to 10000 simulated $F_{\mathrm{ST}}$ values according to the $F_{\mathrm{ST}}$-outlier method using the Selection Workbench (Beaumont \& Nichols 1996). The Microsatellite Toolkit was used to infer levels of genetic diversity, measured as observed $\left(H_{\mathrm{O}}\right)$ and expected $\left(H_{\mathrm{E}}\right)$ levels of heterozygosity (Nei 1987) and average numbers of alleles per locus and sample. Fstat 2.9.3.2 (Goudet 1995) was used to calculate allele frequencies (see Table S1 in the supplement at www.int-res.com/articles/suppl/m416 p035_supp.pdf), allelic richness and inbreeding coefficients partitioned among individuals within each sample $\left(F_{\mathrm{IS}}\right)$, sites within total $\left(F_{\mathrm{ST}}\right)$, and individuals within total $\left(F_{\mathrm{IT}}\right)$, according to Weir \& Cockerham (1984). These tests weigh allele frequencies according to sample size, thus accommodating the fact that samples sizes were not equal. Significance levels of differentiation were corrected using the false discovery rate method (FDR: $\alpha=0.01$ ) (Benjamini \& Hochberg 1995) for multiple comparisons. Temporal changes in genetic diversity were calculated as a percent change, since the sample size for this comparison was too small $(\mathrm{n}=2)$ to allow for statistical analyses to be made. Differences in genetic diversity $\left(H_{\mathrm{E}}, H_{\mathrm{O}}\right.$, and allelic richness) among samples were made using a 2-sided permutation statistic in Fstat 2.9.3.2 (Goudet 1995). The program calculates the average of each statistic $(O S x)$ and then employs a permutation scheme whereby the samples are allocated at random to each group, keeping the number of samples per group constant $\left(S_{X}\right)$. The $\mathrm{p}$-value is calculated as the proportion of randomized datasets where $S x>O S x$.

To validate species delineations and to visualize the uppermost level of population subdivision, the software STRUCTURE v 2.3.3 (Pritchard et al. 2000) was used to infer the most likely number of genetic clusters. The program was run without population information under the admixture model (as individuals may have mixed ancestry) and independent allele frequencies;
10000 burn-ins and $10000 \mathrm{MCM}$ repetitions were run and $K$ (the number of genetic clusters) was set to range from 2 to 13. The most likely value of $K$ was inferred using the method described by Evanno et al. (2005).

\section{RESULTS}

The final data set comprised 13 population samples with a total of 489 unique MLGs (Table 1). Identical MLGs were observed in Acropora pulchra and A. papillare only. The probability of the MLGs being produced by random mating within each population was low $\left(<1 \times 10^{-5}\right)$, indicating that they are likely to be the result of asexual reproduction, most likely through fragmentation or partial mortality isolating portions of encrusting colonies. Three population samples were too small ( $\mathrm{n}<15$ colonies) to warrant inclusion in population level statistical analyses but some non-statistical results from these populations, such as the presence of shared multi-locus genotypes, are considered in the discussion. These samples included $A$. spathulata and $A$. papillare from the 1997 collections at Pelorus and Orpheus and A. pulchra from the 2004 collections at Orpheus. One other member of the Acropora aspera group, A. aspera, does occur on these reefs but was not sampled in large enough numbers to warrant inclusion. Null alleles were observed in a majority of the samples, species and loci. Locus Amil5_007 contained a large proportion of null alleles across all species and populations and was therefore excluded from the analyses. Locus Apam3_166 had null allele frequencies of above $40 \%$ in all populations of $A$. papillare and $A$. pulchra and was excluded from the analyses that involved these 2 species (see Table S2 in the supplement; www.int-res.com/articles/suppl/m416 p035_supp.pdf). Corrected allele frequencies could not be calculated for $A$. papillare due to the small number of population samples; hence, allele frequencies for this species remain uncorrected and thus may inflate pairwise $F_{\mathrm{ST}}$ values that include these 2 samples (between species comparisons and spatial comparison between Orpheus and Pelorus in 2004) (Tables 2 \& 3). The overall $F_{\text {ST }}$ value for the data set changed from $0.317( \pm 0.061)$ before null allele correction to 0.299 $( \pm 0.054)$, post null allele correction; however, the corrections did not change the significance of any of the pairwise population differentiations. It is also apparent that null alleles are a more common issue in the 1997 samples, possibly due to the longer storage of the samples prior to DNA extraction.

Locus specific $F_{\mathrm{ST}}$ values varied no more than expected from stochastic processes and inter-specific differentiations were an order of magnitude larger than the intra-specific values (Table 2). The 2 excep- 
Table 2. Acropora spp. Genetic differentiation partitioned among samples within total $\left(F_{\mathrm{ST}}\right)$ values for each locus partitioned between intra- and inter-specific differentiations. Bold indicates potential $F_{\mathrm{ST}}$ outliers indicative of non-neutrality. Apam3_166 was removed from analyses including Acropora pulchra and A. papillare. Amil2_023 was monomorphic in A. papillare. na: not applicable

\begin{tabular}{|c|c|c|c|c|c|c|c|c|c|}
\hline Locus & $\begin{array}{c}\text { Amil2 } \\
\_002\end{array}$ & $\begin{array}{c}\text { Amil2 } \\
\_006\end{array}$ & $\begin{array}{c}\text { Amil5 } \\
\_028\end{array}$ & $\begin{array}{c}\text { Amil2 } \\
\_022\end{array}$ & $\begin{array}{c}\text { Amil2 } \\
\_023\end{array}$ & $\begin{array}{c}\text { Apam3 } \\
\_166\end{array}$ & $\begin{array}{c}\text { Amil2 } \\
\_010\end{array}$ & $\underset{\_012}{A m i l 2}$ & All \\
\hline \multicolumn{10}{|l|}{ Inter-species } \\
\hline A. millepora & 0.120 & -0.001 & 0.012 & 0.024 & 0.057 & 0.007 & 0.001 & 0.060 & 0.019 \\
\hline A. spathulata & 0.054 & -0.004 & 0.016 & 0.001 & 0.004 & 0.009 & -0.003 & -0.004 & 0.008 \\
\hline A. pulchra & 0.028 & 0.026 & 0.030 & -0.002 & 0.002 & na & 0.012 & 0.029 & 0.022 \\
\hline A. papillare & -0.01 & -0.014 & 0.025 & 0.005 & na & na & -0.013 & 0.030 & 0.005 \\
\hline Intra-species & 0.402 & 0.031 & 0.149 & 0.288 & 0.533 & 0.168 & 0.307 & 0.685 & 0.337 \\
\hline Overall & 0.360 & 0.030 & 0.134 & 0.251 & 0.489 & 0.148 & 0.261 & 0.647 & 0.299 \\
\hline
\end{tabular}

Table 3. Acropora spp. Pairwise population differentiation between Pelorus Island (PI), Orpheus Island (OI) and Fantome Island (FI). 'Not applicable' (na) indicates that a pairwise comparison was not possible due to small or lacking samples. Samples are from 2004 unless otherwise indicated. Bold $F_{\text {ST }}$ values are significantly different from zero $(\mathrm{p}<0.0096$, FDR $\alpha=0.01)$. $F_{\mathrm{ST}}$ : genetic differentiation partitioned among samples within total ${ }_{i}$ FDR: false discovery rate

\begin{tabular}{|lccc|}
\hline & PI/OI & OI/FI & PI/FI \\
\hline A. millepora 1997 & 0.010 & na & na \\
A. millepora & 0.000 & $\mathbf{0 . 0 1 1}$ & $\mathbf{0 . 0 1 3}$ \\
A. pulchra & na & na & $\mathbf{0 . 0 2 7}$ \\
A. papillare & 0.005 & na & na \\
A. spathulata & 0.002 & $\mathbf{0 . 0 0 8}$ & $\mathbf{0 . 0 1 5}$ \\
\hline
\end{tabular}

tions to this were loci Amil2_023 (across all samples) and Amil2_002 (across spatial comparisons in 2004) in A. millepora, which were identified as outliers (p (simulated $F_{\mathrm{ST}}<$ sample $F_{\mathrm{ST}}$ ) $>0.95$ ) and potentially impacted by selection (Table 2). However, the removal of these 2 loci did not change any results and both loci were therefore retained (see Table S3 in the supplement at www.int-res.com/articles/suppl/m416 p035_supp.pdf). All loci were polymorphic and the overall allelic richness, which corrects for variable sample sizes, was $7.99( \pm 2.91 \mathrm{SD})$ alleles per locus (Table 1). Expected levels of heterozygosity varied across samples and species and ranged from 0.289 $( \pm 0.107 \mathrm{SD})$ in $A$. papillare at Pelorus to 0.672 $( \pm 0.096 \mathrm{SD})$ in the 1997 sample of $A$. millepora from Orpheus (Table 1). A significant deficit of heterozygotes in at least one sampled population was apparent in all species (Table 1).

\section{Spatial population genetic structure}

The hypothesis of panmixia could not be rejected for any pairwise comparison between Pelorus and Orpheus (Table 3). One identical multilocus genotype in each of Acropora papillare and A. pulchra was identified from both the Pelorus and Orpheus populations, suggesting dispersal of asexual recruits or fragments in these 2 species across the $14 \mathrm{~m}$ deep and approximately $1000 \mathrm{~m}$ wide channel that separates the 2 sites. A. pulchra was not found in sufficient numbers at Orpheus in 2004 ( $\mathrm{n}=6$ samples) to allow tests of pairwise differentiation between Pelorus and Orpheus, but the Pelorus population was significantly differentiated from its conspecific population at Fantome. Similarly, populations of $A$. millepora and A. spathulata from Fantome were significantly differentiated from their conspecific populations at the 2 northern sites (Table 3). A. papillare was not found in sufficient numbers for population level analyses at the site on Fantome and therefore was not included in this spatial analysis in neither 1997 nor 2004.

\section{Temporal population genetic structure}

The populations of Acropora millepora at Orpheus, A. millepora at Pelorus, and A. pulchra at Pelorus were genetically differentiated between 1997 and 2004 (Table 4). Changes in the levels of genetic diversity $\left(H_{\mathrm{E}}\right)$ were marginal $(-1.0 \%$ for $A$. millepora at Orpheus; $+0.5 \%$ for $A$. millepora at Pelorus; and $+1.1 \%$ for $A$. pulchra at Pelorus). Null alleles were more common in the 1997 than in the 2004 samples of

Table 4. Acropora spp. Level of population differentiation between 1997 and 2004. All $F_{\text {ST }}$ values are significantly different from zero as indicated by bold $(\mathrm{p}<0.0096$, FDR $\alpha=$ 0.01). $F_{\mathrm{ST}}$ : genetic differentiation among samples within total ${ }_{i}$ FDR: false discovery rate

\begin{tabular}{|lcc|}
\hline & $F_{\mathrm{ST}}$ & $\mathrm{p}$ \\
\hline A. millepora PI & $\mathbf{0 . 0 4 9}$ & 0.001 \\
A. millepora OI & $\mathbf{0 . 0 1 7}$ & 0.009 \\
A. pulchra PI & $\mathbf{0 . 0 1 8}$ & 0.003 \\
\hline
\end{tabular}


Table 5. Acropora spp. Differences in diversity between the studied species across all samples measured as observed $\left(H_{\mathrm{O}}\right)$ and expected heterozygosity $\left(H_{\mathrm{E}_{\mathrm{E}}}\right)$, allelic richness $(A)$ and inbreeding coefficient $\left(F_{\mathrm{IS}}\right)$

\begin{tabular}{|lcccc|}
\hline & $H_{\mathrm{O}}$ & $H_{\mathrm{E}}$ & $A$ & $F_{\mathrm{IS}}$ \\
\hline A. millepora & 0.591 & 0.651 & 6.731 & 0.092 \\
A. spathulata & 0.470 & 0.510 & 5.491 & 0.078 \\
A. pulchra & 0.421 & 0.497 & 5.312 & 0.153 \\
A. papillare & 0.136 & 0.249 & 2.739 & 0.452 \\
p-value & 0.005 & 0.004 & 0.006 & 0.013 \\
\hline
\end{tabular}

Table 6. Acropora spp. Matrix of pairwise differentiation between sympatric species. All $F_{\mathrm{ST}}$ values are significantly different from zero as indicated by bold $(\mathrm{p}<0.0096$, FDR $\alpha=$ 0.01). $F_{\mathrm{ST}}$ : genetic differentiation among samples within total; FDR: false discovery rate

\begin{tabular}{|lccc|}
\hline & A. millepora & A. spathulata & A. pulchra \\
\hline A. spathulata & $\mathbf{0 . 1 2 5}$ & & \\
A. pulchra & $\mathbf{0 . 3 2 4}$ & $\mathbf{0 . 3 9 2}$ & \\
A. papillare & $\mathbf{0 . 4 3 0}$ & $\mathbf{0 . 5 3 1}$ & $\mathbf{0 . 2 7 2}$ \\
\hline
\end{tabular}

the same species. One identical MLG was collected both in 1997 and in 2004 in all 3 temporal sample pairs (PID $<0.001$ in all 3 instances).

\section{Genetic diversity}

Genetic diversity, estimated by allelic richness and observed and expected heterozygosities, varied significantly among species, with Acropora millepora being the most and A. papillare the least genetically diverse (Table 5). Pairwise comparisons of levels of genetic diversity revealed no significant differences between A. millepora and A. spathulata, or between A. millepora and A. pulchra.

\section{Species boundaries}

Based on $F_{\text {ST }}$ values, the 4 species were all genetically significantly differentiated from one another (Table 6). This includes sympatric populations of Acropora millepora and A. spathulata from all 3 sites, confirming the current species status of A. spathulata. However, the species delineation between $A$. papillare and A. pulchra is less clear. At NE Pelorus, these 2 species shared one identical multilocus genotype. Furthermore, despite the observation of significant $F_{\mathrm{ST}}$ values, the Bayesian clustering analysis performed with the package STRUCTURE indicates the highest probability for 3 instead of 4 genetic clusters within the 4 species and fails to subdivide A. papillare and A. pulchra (Fig 4).

\section{DISCUSSION}

\section{Spatial population genetic structure}

Our study revealed similar spatial patterns of genetic structure in 4 species of coral in the Acropora aspera group. The apparent lack of genetic differentiation between populations at Pelorus and Orpheus Islands suggests that migration occurs across the $14 \mathrm{~m}$ deep and $1000 \mathrm{~m}$ wide channel that separates these sites. Significant genetic differentiation was detected for all pairwise comparisons between the 2 northerly populations at Pelorus and Orpheus and the one at Fantome, despite the fact that this island is located only $11 \mathrm{~km}$ to the south. Such small-scale differentiation is not commonly reported for broadcast spawning corals whose gametes and larvae spend at least 3 to $4 \mathrm{~d}$ in the water column prior to becoming competent to settle (Nishikawa et al. 2003), during which time they can disperse tens of kilometres (Willis \& Oliver 1988, Gilmour et al. 2009). Furthermore, larvae of broadcast spawning corals can survive for 6 to 8 mo in the laboratory (Graham et al. 2008), suggesting that they may disperse over much greater distances. Prevailing hydrodynamic conditions in the shallow near-shore environment have a strong influence on dispersal, retention and settlement (Cowen \& Sponaugle 2009), but currently available models are insufficient to predict the hydrodynamics inside the bays that we sampled (Largier 2003, Gawarkiewicz et al. 2007). Nevertheless, our results provide support to Cowen and Sponaugle's recent conclusion that realised dispersal distances are not simply a function of planktonic larval duration, but are determined by complex interactions between numerous physical and biological parameters, including hydrodynamics, selection and habitat availability (Cowen \& Sponaugle 2009).

Because of lack of replication in the sampling design, it is not possible to discern whether the small-scale patterns of genetic differentiation found in this study are typical of these species or simply reflect past events at these specific sites. For example, in 2004, the site at Fantome Island was still recovering from the 1998 coral beaching event. It is plausible, therefore, that differentiation between this site and the 2 northerly sites resulted from a difference in the genetic composition of remnant populations or newly recruited colonies at each site following the 1998 bleaching and that there had been insufficient gene flow between them to erase this difference after 6 yr. Conversely, given that panmixia between Pelorus and Orpheus could not be rejected, it may be that divergence associated with similar random reductions within each population and its associated allele frequencies have been erased due to the proximity of these populations to each other. 

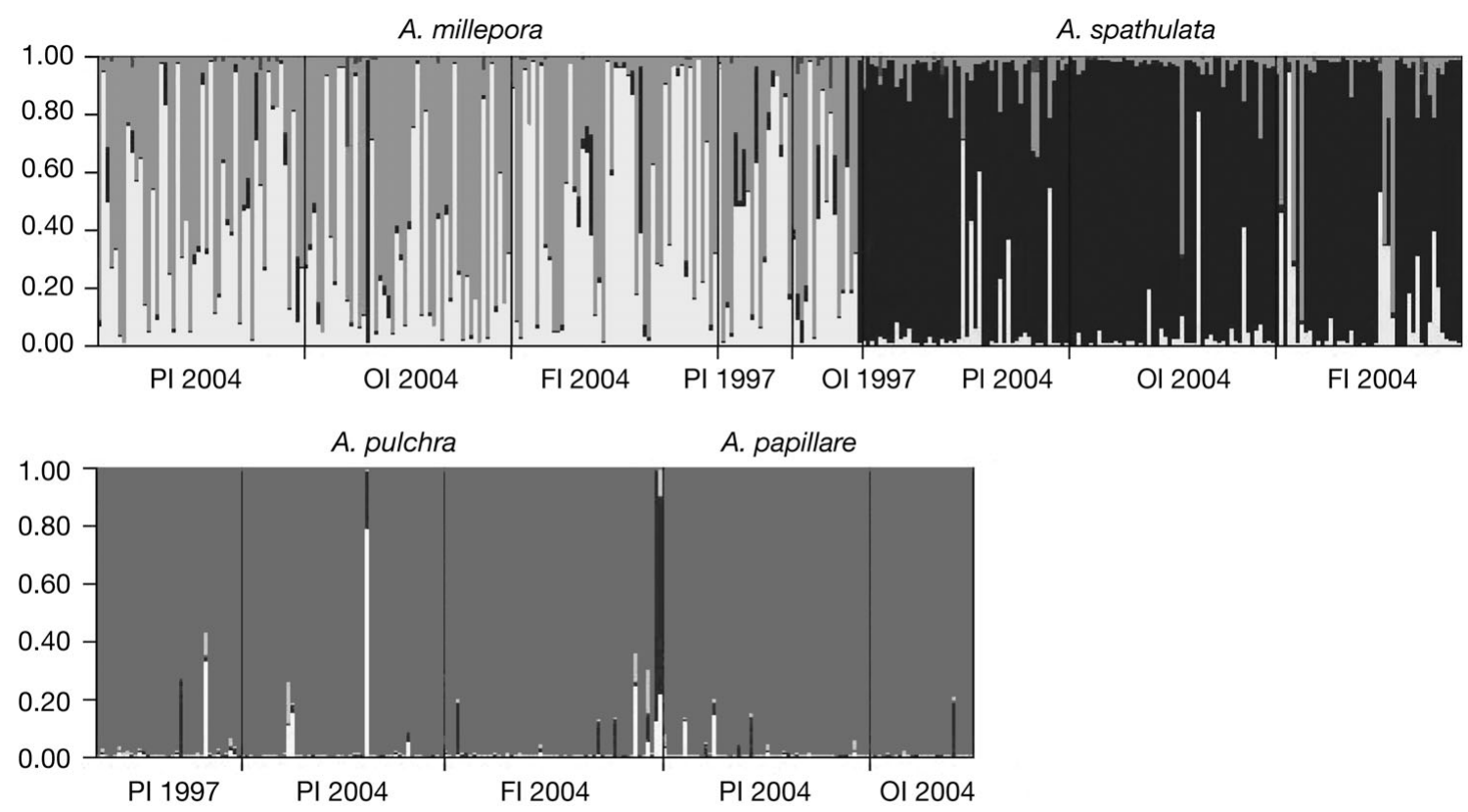

Fig. 4. Bayesian model-based cluster analysis of the Acropora millepora, A. spathulata, A. pulchra, and A. papillare populations as implemented in STRUCTURE v2.3.3 with $K$ (most likely number of genetic clusters) being set at 4 . Each individual colony is represented by a vertical bar. Sampling locations and year are given along the $x$-axis, and are separated by black lines (PI: Pelorus Island; OI: Orpheus Island; FI: Fantome Island). The level of genetic differentiation between A. papillare and A. pulchra is weak, but these 2 species are both clearly distinct from A. millepora and A. spathulata, which are also genetically distinct from one another

Site-specific selection is a potential explanation for genetic differentiation such as that observed between the southern Fantome population and the 2 northern populations. Although on the windward side of the island, the Fantome site is sheltered within an embayment and by an adjacent island, whereas the sites on Pelorus and Orpheus are exposed to prevailing southeasterly winds. Such habitat variation may affect the population genetic structure and distribution of species. For example, genetic differentiation in the coral Pocillopora damicornis between lagoonal and reef slope sites has previously been attributed to habitatspecific selection (Benzie et al. 1995). Also, Acropora papillare, which is restricted to shallow, exposed reef environments is only rarely encountered at the most exposed edges of NE Fantome reef, further emphasizing the different nature of this site. Localised selection may lead to divergence between populations for loci under selection and loci linked to these. Neutral loci, however, should remain panmictic (Nosil et al. 2009). The degree of divergence varied among loci in the present study with 2 loci showing $F_{\mathrm{ST}}$ values indicative of selection (non-neutrality) in A. millepora (Amil2_002, Amil2_023). Removing these 2 loci, however, did not alter the statistical significance of any pairwise comparison, supporting the idea that factors other than selection are likely to have played a part in the levels of differentiation observed here.

\section{Temporal population genetic structure}

Population genetic composition changed significantly between 1997 and 2004 at the sampled sites in both Acropora millepora and A. pulchra. High levels of bleaching-related mortality is likely to have exerted considerable selection against less thermally tolerant colonies, in the 4 species examined which is expected to have led to genetic changes within these populations at affected, non-neutral loci (Schmidt et al. 2008). However, this study is based on neutral genetic markers that showed mostly consistent levels of divergence across loci, making it more likely that the observed genetic divergence is the result of random genetic drift.

The presence of identical MLGs in both years indicates that some colonies survived the extensive 1998 bleaching, which reduced population sizes to almost zero for many Acropora species at these sites (Page 1999). Coral colonies that recover from bleaching tend to show decreased fecundity (Michalek-Wagner \& Willis 2001, Baker et al. 2008) and re-generation of damaged tissue slows down growth (Mascarelli \& Bunkley-Williams 1999). However, despite the devastating effect of the 1998 coral bleaching on these 4 species in this area, none of our temporal comparisons show an obvious reduction in genetic diversity $\left(H_{\mathrm{E}}\right)$ between 1997 and 2004. It should be noted that this change cannot be statistically tested due to the low 
number of temporal comparisons and should be regarded with some caution. If a proportion of the bleached colonies retained even a small remnant of live tissue, this will contribute to the maintenance of genetic diversity as some of the original genotypes will remain within the surviving population. Recovery through regrowth of remnant tissues has been reported for staghorn colonies of Acropora in the southern GBR following bleaching-induced mortality (Diaz-Pulido et al. 2009). The same mechanism for recovery may be available to other Acropora species, including the ones studied here. In addition it is likely that larvae from unsampled reefs within dispersal distance contributed to the recovery and further contribute to the change in genetic composition. Such a scenario could explain the maintenance of overall genetic diversity and the resampling of identical MLGs, while allowing for an overall change in genetic composition through influx of new genetic material coupled with a change in the relative frequency and reproductive output of remnant colonies. The prevalence of temporally unique alleles is higher in the 2004 samples but this is most likely an effect of the larger sample sizes from this year, which would uncover more rare alleles compared to the 1997 collections. Indeed, a majority of these unique alleles occur at a low frequency. The skewed samples sizes should not impact on the $F_{\mathrm{ST}}$ values as statistical calculations were implemented in a manner that corrects for such differences.

\section{Genetic diversity and species boundaries}

Estimating genome-wide diversity requires the use of large numbers of both neutral and functional markers spread out across the genome, and may not necessarily be correlated to microsatellite diversity (Vali et al. 2008). Furthermore, the ascertainment bias in the selection of loci, which were developed for one of the study species (Acropora millepora), means that these markers are likely to show reduced levels of heterozygosity when applied to different species or even populations different from those for which they were developed (Vali et al. 2008). Another consequence of using markers developed for a particular species is that the prevalence of null alleles may be greater in the nontarget species, further adding to a potential reduction in measured diversity. The large number of failed amplifications in locus Apam3_166 may indicate that this is indeed the case; however, other loci show similar frequencies of nulls across all 4 species. It can be postulated, however, that the seemingly low genetic diversity of $A$. papillare is a reflection of it being a rare species (Richards et al. 2008) and hence prone to loss of alleles through random genetic drift as a consequence of small effective population size. Low genetic diversity coupled with rarity indicates that $A$. papillare may be at greater risk of extinction and less likely to adapt to a changing environment than the other 3 species studied here.

Despite often playing an important evolutionary role in both plant and animal taxa, the role of hybridisation in enhancing genetic and species diversity and ecosystem resilience remains a controversial topic (Allendorf et al. 2001). In corals, however, the link between morphological and genetic species is often unclear and in the genus Acropora, hybridisation and introgression have played an important evolutionary role (Willis et al. 2006). Indeed, A. papillare is one of at least 3 rare Indo-Pacific coral species likely to have arisen through hybridisation (Richards et al. 2008). In this study, the 4 species were collected and defined using morphological characters (Wallace 1999). A. papillare and A. pulchra typically occupy distinct habitats (reef crests versus inner reef flats, respectively), although they may co-occur on the outer reef flat and they are crossfertile in no-sperm-choice fertilisation experiments (van Oppen et al. 2002). In this study, the 2 species shared a multilocus genotype and failed to separate as 2 distinct clusters in the Bayesian clustering analysis, despite showing significant $F_{\mathrm{ST}}$ values. Future research should focus on examining the genetic distinctiveness of these 2 species in detail.

In summary, we have shown that genetic structure is present at small spatial scales in species of the coral genus Acropora in the Palm Islands, despite the fact that these species are broadcast spawners with planktonic larvae that remain competent for several weeks. Furthermore, the 1998 coral bleaching changed the genetic composition of the 3 species that were sampled prior to 1998, but did not lead to considerable losses of genetic diversity at the loci examined.

Acknowledgements. The corals in the study were sampled under GBRMPA permit no G99/441. The project was funded by the Marine Tropical Sciences Research Facility (MTSRF), the Australian Institute of Marine Science (AIMS), James Cook University (JCU) and the Australian Research Council (an ARC DP to B.L.W.). Thanks to the late T. van Rheede for his help with collection of the 1997 samples. The figures were created with the help of T. Simmonds.

\section{LITERATURE CITED}

Allendorf FW, Leary RF, Spruell P, Wenburg JK (2001) The problems with hybrids: setting conservation guidelines. Trends Ecol Evol 16:613-622

Arnaud-Haond S, Belkhir K (2007) GENCLONE: a computer program to analyse genotypic data, test for clonality and describe spatial clonal organization. Mol Ecol Notes 7:15-17

Baird AH, Marshall PA (2002) Mortality, growth and reproduction in scleractinian corals following bleaching on the 
Great Barrier Reef. Mar Ecol Prog Ser 237:133-141

Baker AC, Glynn PW, Riegl B (2008) Climate change and coral reef bleaching: an ecological assessment of longterm impacts, recovery trends and future outlook. Estuar Coast Shelf Sci 80:435-471

Beaumont MA, Nichols RA (1996) Evaluating loci for use in genetic analysis of population structure. Proc Biol Sci 263: 1619-1626

Benjamini Y, Hochberg Y (1995) Controlling the false discovery rate: a practical and powerful approach to multiple testing. J R Stat Soc, B 57:289-300

> Benzie JAH, Haskell A, Lehman H (1995) Variation in the genetic composition of coral (Pocillopora damicornis and Acropora palifera) populations from different reef habitats. Mar Biol 121:731-739

Bourne DG, Garren M, Work TM, Rosenberg E, Smith GW, Harvell CD (2009) Microbial disease and the coral holobiont. Trends Microbiol 17:554-562

Cowen RK, Sponaugle S (2009) Larval dispersal and marine population connectivity. Annu Rev Mar Sci 1:443-466

> Day T, Nagel L, Van Oppen MJH, Caley MJ (2008) Factors affecting the evolution of bleaching resistance in corals. Am Nat 171:E72-E88

Diaz-Pulido G, McCook LJ, Dove S, Berkelmans R and others (2009) Doom and boom on a resilient reef: climate change, algal overgrowth and coral recovery. PLoS ONE 4:e5239

Donner SD, Skirving WJ, Little CM, Oppenheimer M, HoeghGuldberg O (2005) Global assessment of coral bleaching and required rates of adaptation under climate change. Global Change Biol 11:2251-2265

Evanno G, Regnaut S, Goudet J (2005) Detecting the number of clusters of individuals using the software STRUCTURE: a simulation study. Mol Ecol 14:2611-2620

Flot JF, Licuanan WY, Nakano Y, Payri C, Cruaud C, Tillier S (2008) Mitochondrial sequences of Seriatopora corals show little agreement with morphology and reveal the duplication of a tRNA gene near the control region. Coral Reefs 27:789-794

Gawarkiewicz G, Monismith S, Largier J (2007) Observing larval transport processes affecting population connectivity progress and challenges. Oceanography 20:40-53

Gilmour JP, Smith LD, Brinkman RM (2009) Biannual spawning, rapid larval development and evidence of self-seeding for scleractinian corals at an isolated system of reefs. Mar Biol 156:1297-1309

Goudet J (1995) Fstat (version 1.2); a computer program to calculate F-statistics. J Hered 86:485-486

Graham EM, Baird AH, Connolly SR (2008) Survival dynamics of scleractinian coral larvae and implications for dispersal. Coral Reefs 27:529-539

Gralton C (2001) Coral recovery on inshore reefs in the Palm Islands following the 1998 coral bleaching event. Honours thesis, James Cook University,Townsville

Hoegh-Guldberg O (1999) Climate change, coral bleaching and the future of the world's coral reefs. Mar Freshw Res 50:839-866

$>$ Hughes TP, Baird AH, Bellwood DR, Card M and others (2003) Climate change, human impacts, and the resilience of coral reefs. Science 301:929-933

> Largier JL (2003) Considerations in estimating larval dispersal distances from oceanographic data. Ecol Appl 13:71-89

> Lough JM (2008) 10th anniversary review: a changing climate for coral reefs. J Environ Monit 10:21-29

Marshall PA, Baird AH (2000) Bleaching of corals on the Great Barrier Reef: differential susceptibilities among taxa. Coral Reefs 19:155-163

Mascarelli PE, Bunkley-Williams L (1999) An experimental field evaluation of healing in damaged, unbleached and artificially bleached star coral, Montastraea annularis. Bull Mar Sci 65:577-586

> Michalek-Wagner K, Willis BL (2001) Impacts of bleaching on the soft coral Lobophytum compactum. I. Fecundity, fertilization and offspring viability. Coral Reefs 19: 231-239

Miller K, Babcock R (1997) Conflicting morphological and reproductive species boundaries in the coral genus Platygyra. Biol Bull 192:98-110

> Mydlarz LD, McGinty ES, Harvell CD (2010) What are the physiological and immunological responses of coral to climate warming and disease? J Exp Biol 213:934-945

Nei M (1987) Molecular evolutionary genetics. Columbia University Press, New York, NY

Nishikawa A, Katoh M, Sakai K (2003) Larval settlement rates and gene flow of broadcast-spawning (Acropora tenuis) and planula-brooding (Stylophora pistillata) corals. Mar Ecol Prog Ser 256:87-97

$>$ Nosil P, Funk DJ, Ortiz-Barrientos D (2009) Divergent selection and heterogeneous genomic divergence. Mol Ecol 18: 375-402

Oliver JK, Berkelmans R, Eakin CM (2009) Coral bleaching in space and time. In: van Oppen MJH, Lough JM (eds) Coral bleaching: patterns, processes, causes and consequences, Vol 205. Springer-Verlag, Berlin, p 21-40

Page C (1999) Impacts of the 1998 bleaching event on abundance, reproduction and recruitment of scleractinian corals. Honours thesis, James Cook University, Townsville

> Pannell JR, Charlesworth B (1999) Neutral genetic diversity in a metapopulation with recurrent local extinction and recolonization. Evolution 53:664-676

- Pannell JR, Charlesworth B (2000) Effects of metapopulation processes on measures of genetic diversity. Phil Trans $\mathrm{R}$ Soc Lond B 355:1851-1864

Park SDE (2001) Trypanotolerance in West African cattle and the population genetic effects of selection. Honours thesis, University of Dublin

> Pritchard JK, Stephens M, Donnelly P (2000) Inference of population structure using multilocus genotype data. Genetics 155:945-959

Richards ZT, van Oppen MJH, Wallace CC, Willis BL, Miller DJ (2008) Some rare Indo-pacific coral species are probable hybrids. PLoS ONE 3:e3240

> Schmidt PS, Serrao EA, Pearson GA, Riginos C and others (2008) Ecological genetics in the North Atlantic: environmental gradients and adaptation at specific loci. Ecology 89:S91-S107

Souter P (2010) Hidden genetic diversity in a key model species of coral. Mar Biol 157:875-885

Vali U, Einarsson A, Waits L, Ellegren H (2008) To what extent do microsatellite markers reflect genome-wide genetic diversity in natural populations? Mol Ecol 17:3808-3817

van Oosterhout C, Hutchinson WF, Wills DPM, Shipley P (2004) MICRO-CHECKER: software for identifying and correcting genotyping errors in microsatellite data. Mol Ecol Notes 4:535-538

van Oppen MJH, Gates RD (2006) Conservation genetics and the resilience of reef-building corals. Mol Ecol 15: 3863-3883

van Oppen MJH, Willis BL, van Vugt H, Miller DJ (2000) Examination of species boundaries in the Acropora cervicornis group (Scleractinia, Cnidaria) using nuclear DNA sequence analyses. Mol Ecol 9:1363-1373

van Oppen MJH, Willis BL, Van Rheede T, Miller DJ (2002) Spawning times, reproductive compatibilities and genetic structuring in the Acropora aspera group: evidence for 
natural hybridization and semi-permeable species boundaries in corals. Mol Ecol 11:1363-1376

van Oppen MJH, Underwood JN, Muirhead AN, Peplow L (2007) Ten microsatellite loci for the reef-building coral Acropora millepora (Cnidaria, Scleractinia) from the Great Barrier Reef, Australia. Mol Ecol Notes 7:436-438

Veron J (2000) Corals of the world. Australian Institute of Marine Science, Townsville

Wallace CC (1999) Staghorn corals of the world: a revision of the coral genus Acropora (Scleractinia; Astrocoeniina; Acroporidae) worldwide, with emphasis on morphology, phylogeny and biogeography. CSIRO Publishing, Melbourne

Weir BS, Cockerham CC (1984) Estimating F-statistics for the analysis of population structure. Evolution 38: $1358-1370$

Weis VM (2008) Cellular mechanisms of Cnidarian bleaching: stress cause a breakdown of symbiosis. J Exp Biol 211:

Editorial responsibility: Karen Miller,

Hobart, Tasmania, Australia
3059-3066

Wilkinson C (ed) (2008) Status of coral reefs of the world: 2008. Global Coral Reef Monitoring Network and Reef and Rainforest Research Center, Townsville

Willis BL, Oliver JK (1988) Inter-reef dispersal of coral larvae following the annual mass spawning on the Great Barrier Reef. Proc 6th Int Coral Reef Symp 2:853-859

Willis BL, Babcock RC, Harrison PL, Wallace CC (1997) Experimental hybridization and breeding incompatibilities within the mating systems of mass spawning reef corals. Coral Reefs 16:S53-S65

Willis BL, van Oppen MJH, Miller DJ, Vollmer SV, Ayre DJ (2006) The role of hybridization in the evolution of reef corals. Annu Rev Ecol Evol Syst 37:489-517

Wilson K, Whan V, Lehnert S, Byrne K and others (2002) Genetic mapping of the black tiger shrimp Panaeus monodon with amplified fragment length polymorphism. Aquaculture 204:297-309

Submitted: November 5, 2009; Accepted: July 20, 2010

Proofs received from author(s): September 27, 2010 